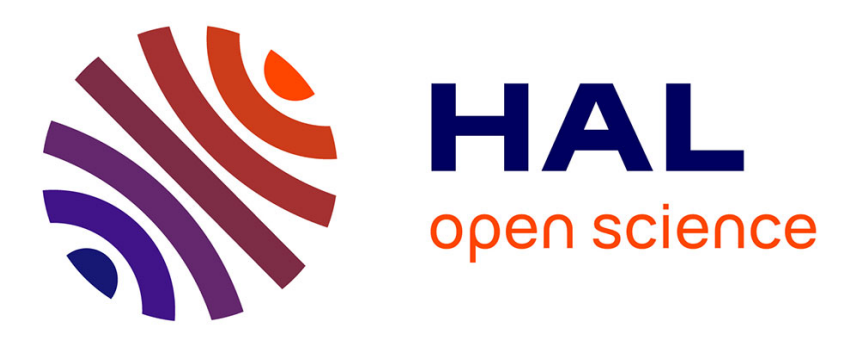

\title{
Comparative study of PEM fuel cell models for integration in propulsion systems of urban public transport
}

Pablo Garcia, Luis Fernandez, Carlos A Garcia, Francisco Jurado

\section{- To cite this version:}

Pablo Garcia, Luis Fernandez, Carlos A Garcia, Francisco Jurado. Comparative study of PEM fuel cell models for integration in propulsion systems of urban public transport. Fuel Cells, 2010, 10 (6), pp.1024. 10.1002/fuce.201000002 . hal-00574808

\section{HAL Id: hal-00574808 https://hal.science/hal-00574808}

Submitted on 9 Mar 2011

HAL is a multi-disciplinary open access archive for the deposit and dissemination of scientific research documents, whether they are published or not. The documents may come from teaching and research institutions in France or abroad, or from public or private research centers.
L'archive ouverte pluridisciplinaire HAL, est destinée au dépôt et à la diffusion de documents scientifiques de niveau recherche, publiés ou non, émanant des établissements d'enseignement et de recherche français ou étrangers, des laboratoires publics ou privés. 
Comparative study of PEM fuel cell models for integration in propulsion systems of urban public transport

\begin{tabular}{|c|c|}
\hline Journal: & Fuel Cells \\
\hline Manuscript ID: & fuce.201000002.R2 \\
\hline Wiley - Manuscript type: & Original Research Paper \\
\hline $\begin{array}{l}\text { Date Submitted by the } \\
\text { Author: }\end{array}$ & 23-Apr-2010 \\
\hline Complete List of Authors: & $\begin{array}{l}\text { Garcia, Pablo; University of Cadiz } \\
\text { Fernandez, Luis; University of Cadiz } \\
\text { Garcia, Carlos; University of Cadiz } \\
\text { Jurado, Francisco; University of Jaen, Electrical Engineering }\end{array}$ \\
\hline Keywords: & $\begin{array}{l}\text { Vehicle Application, Theoretical Model, Control, Fuel Cell } \\
\text { Application, Hydrogen Storage }\end{array}$ \\
\hline
\end{tabular}

\section{s) ScholarONE \\ Manuscript Central}




\title{
Comparative study of PEM fuel cell models for integration in propulsion systems of urban public transport
}

\author{
Pablo Garcia ${ }^{1}$, Luis M. Fernández ${ }^{1}$, Carlos A. Garcia ${ }^{1}$, Francisco Jurado ${ }^{2 *}$ \\ ${ }^{1}$ Department of Electrical Engineering, University of Cadiz, EPS Algeciras, Avda. Ramon Puyol, s/n. \\ 11202 Algeciras (Cadiz), Spain. \\ ${ }^{2}$ Department of Electrical Engineering, University of Jaen, EPS Linares, C/ Alfonso X, nº 28. 23700 \\ Linares (Jaen), Spain.
}

Received January 11, 2010

[*] Corresponding author, fjurado@ujaen.es

\begin{abstract}
In this paper, a comparative study of three proton exchange membrane (PEM) fuel cell (FC) models is performed in order to choose the best model for its integration in the modelling of the hybrid propulsion system of a tramway. Two reduced models of PEM FC system are studied in this work: 1) a new reduced model obtained from a complete one is here presented (reduced model 1); and 2) a reduced model very used for hybrid vehicles and portable applications (reduced model 2). These models are evaluated when integrated in the tramway hybrid system by comparing the simulated responses with that one of a complete model, which includes a detailed dynamic model of the main components of FC system. Steady state and dynamic simulations are performed in order to compare the models. Considering the external response of FC system integrated in the tramway hybrid system, both reduced models show similar results with an important reduction of computation time with respect to the complete model. However, the reduced model 1 shows better results than the reduced model 2 when representing the internal behaviour of FC system, so that this model is considered the most appropriate for propulsion system applications.
\end{abstract}

Keywords: Fuel cell application, hydrogen storage, theoretical model, vehicle application.

\section{Introduction}

FC promises as the best future replacement for internal combustion engine in transportation applications, because they operate more efficiently and with low emissions. The use of this clean power source mainly focuses on public transport (buses, trains, tramways and undergrounds) and passenger vehicles, where the FC is the main power generation system and a rechargeable battery is used as auxiliary power device. Among all types, PEM FC is the best option to be used in public transport due to their high power density, specific power, low operating temperature, longevity, efficiency, good dynamic behaviour and the ability to rapidly adjust to changes in power demand $[1,2]$.

A complete model including a detailed dynamic model of the main components of PEMFC system, such as described in [3], can be used to represent its behaviour. However, reduced models have been developed in order to approximate the FC response, and thus enabling reduced computation time. A quite complete model is described in [4], where a screw compressor is modelled, and in addition, three valves are used: a valve to control the entering hydrogen, another one controls the cathode pressure, and the third one controls the hydrogen leaving the anode. More reduced models are used by [5--8], where the concentration voltage drops are not considered and the compressor is not modelled. In [9], a second order dynamic system represents the rotational dynamics associated with the lumped model of compressor and motor, and a pressure dependent static map is used to calculate the mass flow of the compressor. Furthermore, a reduced model for stand-alone applications is described in [10], where the compressor is replaced by a second order function that calculates the needed hydrogen from the methanol.

This paper presents a comparative study of PEM FC models for integration in hybrid propulsion systems of urban public transport, based on a commercial FC from Nuvera, which is especially manufactured for this application [11]. A new reduced model is proposed and compared with one of most used reduced model for hybrid vehicles and portable applications. Both reduced models are evaluated when integrated in a FC-battery powered hybrid system for a real surface tramway. Furthermore, the 
modelling of the other components of the hybrid propulsion system and a new EMS for the hybrid tramway are presented in this paper. The reduced models are evaluated by means of simulations, where their responses are compared with that one of the complete model described in [3], which includes a detailed dynamic model of the main components of FC system. The drive cycle and the demanded load used in the dynamic simulations belong to the Metro Centro tramway that actually serves the centre of Seville, a city in Spain. It operates currently as a catenary-powered tramway in the center of Seville. One of the objectives of the Ecotrans research project, which is being carried out by a Spanish consortium and is funded by the Spanish Ministry of Science and Technology, is to retrofit the current tramway to an FCbattery hybrid tramway. This paper presents the first advances made in the modelling and control of the new hybrid system.

\section{Modelling PEM Fuel Cell System}

A commercial FC from Nuvera [11] is considered in this work for its application in the hybrid system which drives the tramway. FC selected generates a nominal power of $127 \mathrm{~kW}-235 \mathrm{~V}$, so that two of these FCs are connected in parallel in order to achieve a total net power around of $200 \mathrm{~kW}^{1}$.

Three models of a PEM FC system are described in this section. The first one is a complete model which includes a detailed dynamic model of the main components of PEM FC system, as described in [3]. The second one corresponds to a new reduced model proposed in this paper, which is obtained from application of some simplifications to the complete model. The third one is a more reduced model, which is very used for hybrid vehicles and portable applications.

\subsection{Complete Model}

The complete model (CM) is composed of:

- A compressor with a DC motor, which controls the incoming air (oxygen) to the cathode. The compressor is modelled by a static map which determines the air flow incoming into the cathode.

- Four manifolds (two supply and two return manifolds) which keep a stable gas flow. The models are derived from application of the mass conservation principle in each manifold.

- The air cooler does not address heat transfer effect and maintains the temperature of the air entering at $80^{\circ} \mathrm{C}$. Thus, also the humidity of the gas existing is changed in the air cooler.

- A humidifier which injects water into the membrane avoiding the loss of membrane properties. The model uses the thermodynamic properties of gas mixtures to calculate the condition of the flow entering the cathode.

- A high pressure tank provides the hydrogen to the FC through a valve. It is controlled by a proportional control based on the pressure difference.

The PEMFC model is completed with an electrochemical model to calculate the FC output voltage, which requires the effective partial pressures of the electrodes to be determined. The partial pressures of the anode and cathode are calculated from the mass conservation law and ideal gas law. In case of the anode, it has been considered that the unused hydrogen inside the anode is returned to the inlet through a recirculation pump. On the other hand, a valve for the purging of the hydrogen is commonly used in real FCs in order to eliminate the impurities that gradually accumulate near the exhaust outlet. This purging is programmed either as a function of cell voltage or as a function of time $[12,13]$. In this work, the modelling of the pump and the purging of the hydrogen has not been considered.

In addition, the FC output voltage is obtained from the sum of the Nernst's voltage, the activation voltage drop, the ohmic voltage drop and the concentration voltage drop, where all the voltage drops are function of the current density. A more detailed dynamic model of the main components of FC system is described in [3]. Figure 1 shows the configuration of the PEM FC complete model implemented in this work.

\subsection{Reduced Model 1}

Applying some simplifications to the previous complete model, a reduced model of PEMFC (reduced model 1, RM1) can be obtained. In this work, the following simplifications have been done:

- The gases are considered ideal.

- The FC is fed with hydrogen and air.

- The electrode channels are small enough so that the pressure drop across them is negligible.

\footnotetext{
${ }^{1}$ For this work, the total net power is the power generated by the FC minus the power consumed by the compressor.
} 
- The exhaust of each channel is via a single orifice. The ratio of pressures between the interior and exterior of the channel is large enough to consider that the orifice is choked.

- Assuming that inlet oxygen and hydrogen coming respectively from compressor and tank present a stable mass flow, the supply manifolds have been eliminated.

- Return manifolds have been removed since the outlet flow of any gas is considered to be proportional to its partial pressure inside the channel.

- The humidifier and air cooler are considered ideal so that the FC operates at optimum temperature $\left(80^{\circ} \mathrm{C}\right)$ and with constant relative humidity.

- The compressor is modelled by a first order system in order to approximate its dynamic response.

The FC system is composed of the FC core associated with all the auxiliary services necessary for an embedded FC system. The FC core consists of the anode and cathode blocks, which calculates the hydrogen and oxygen partial pressure, respectively, and the stack voltage model. The auxiliary services are the compressor with DC motor controlling the air flow (oxygen) to the cathode and a hydrogen valve controlling the hydrogen input flow. Figure 2 shows the configuration of this reduced model.

\subsubsection{Anode Model}

The reaction that occurs in the FC anode is the oxidation of hydrogen (supplied from a tank) by releasing electrons to the conductive electrode and on through the external load. The hydrogen partial pressure in the anode is calculated from the mass conservation law and ideal gas law.

$$
\frac{d p_{H 2}}{d t}=\frac{R_{H 2} \cdot T}{V_{a n}}\left(q_{H 2}^{\text {in }}-q_{H 2}^{\text {out }}-q_{H 2}^{r}\right)
$$

where $q_{H 2}{ }^{r}$ is obtained from the Faraday`s law.

$$
q_{H 2}^{r}=\frac{N_{\text {cell }} \cdot I_{F C}}{2 \cdot F}
$$

The hydrogen output flow $q_{\mathrm{H} 2}{ }^{\text {out }}$ is the unused hydrogen inside the anode and it is calculated imposing the desired utilization factor (relationship between the hydrogen that reacts and the incoming hydrogen, $U_{f}$ ). Desired utilization factor of hydrogen has been selected from the characteristics of the commercial FC used in this work [11], where a value around of $1 / 3$ is recommended for the FC.

$q_{H 2}^{\text {out }}=q_{H 2}^{r}\left(\frac{1}{U_{f}}-1\right)$

where

$$
U_{f}=q_{H 2}^{r} / q_{H 2}^{i n}
$$

The hydrogen input flow $q_{\mathrm{H} 2}{ }^{\text {in }}$ is calculated as the sum of the hydrogen flow that provides the tank through the hydrogen input valve $q_{H_{2}}{ }^{\text {valve }}$ and the hydrogen back flow (the hydrogen that does not react), $q_{H 2}{ }^{\text {back }}$.

$$
q_{H 2}^{\text {in }}=q_{H 2}^{\text {valve }}+q_{H 2}^{\text {back }}
$$

The valve is controlled in order to minimize the difference of pressure between the anode and cathode [5, $6,14]$. Fig. 3 shows the control scheme of this valve. The molar flow of this valve $q_{H_{2}}$ valve is expressed as a function of the opening section $S_{\text {open }}$ and a constant $k_{\text {valve }}$ which varies depending on the difference of pressure between the anode and cathode.

$q_{\mathrm{H} 2}^{\text {valve }}=S_{\text {open }} \cdot k_{\text {valve }}$

Finally, the global utilization factor is defined as the ratio between the hydrogen flow that reacts and the hydrogen flow through the valve.

$$
U_{f g}=q_{H 2}^{r} / q_{H 2}^{\text {valve }}
$$

\subsubsection{Cathode Model}

In the $\mathrm{FC}$ cathode, the reaction that occurs is the reduction of oxygen in air by receiving electrons. Similarly, the oxygen partial pressure in the cathode can be also obtained from the mass conservation law and ideal gas law.

$$
\frac{d p_{O 2}}{d t}=\frac{R_{O 2} \cdot T}{V_{c a t}}\left(q_{O 2}^{\text {in }}-q_{O 2}^{\text {out }}-q_{O 2}^{r}\right)
$$


$q_{O 2}^{r}=\frac{N_{\text {cell }} \cdot I_{F C}}{4 \cdot F}$

The oxygen output flow $q_{O 2}{ }^{\text {out }}$ is calculated from the relation between the molar flow of oxygen and its partial pressure inside the channel $[6,7,14]$. This relation can be expressed as follows:

$\frac{q_{O 2}}{p_{O 2}}=\frac{K_{c a t}}{\sqrt{M_{O 2}}}=K_{O 2}$

$q_{O 2}^{\text {out }}=K_{O 2} \cdot p_{O 2}$

Another difference with respect to the $\mathrm{CM}$ resides in the way of calculating the total pressures in the anode and cathode. In the $\mathrm{CM}$, the masses balance is performed for each element which appears in the process (nitrogen, water and oxygen in the cathode and water and hydrogen in the anode). Whereas the total pressures in the anode and cathode are obtained in this reduced model from the following expressions:

$$
\begin{aligned}
& p_{a n}=p_{H 2}+p_{H 2 O} \\
& p_{c a t}=p_{O 2}+p_{N 2}+p_{H 2 O}=p_{O 2}+p_{O 2} \cdot K_{t e}+p_{H 2 O}
\end{aligned}
$$

where the water partial pressure $p_{\mathrm{H} 2 \mathrm{O}}$ is assumed constant, and the nitrogen partial pressure $p_{\mathrm{N} 2}$ is considered proportional to the oxygen partial pressure. The proportional constant has been obtained from the average value between these two pressures along the channel of the CM.

\subsubsection{FC Voltage Model}

The FC output voltage $V_{f c}$ is calculated as the product of the number of cells $N_{\text {cell }}$ and cell voltage $V_{\text {cell }}$. The cell voltage can be expressed from the Nernst's instantaneous voltage $E_{\text {cell }}$ and the irreversible voltage or the loss voltage $V_{\text {irrev }}[10,15]$ :

$$
\begin{aligned}
& V_{f c}=N_{\text {cell }} \cdot V_{\text {cell }} \\
& V_{\text {cell }}=E_{\text {cell }}-V_{\text {irrev }} \\
& E_{\text {cell }}=E_{\text {cell }}^{0}-k_{e} \cdot\left(T-T_{\text {ref }}\right)-\frac{R_{g} \cdot T}{2 \cdot F} \ln \left(\frac{p_{H 20}}{p_{02}^{0.5} \cdot p_{H 2}}\right) \\
& V_{\text {irrev }}=V_{\text {act }}+V_{\text {conc }}+V_{\text {ohm }}
\end{aligned}
$$

where $k_{e}$ is a function of the entropy change and the Faraday`s constant.

The irreversible voltage $V_{\text {irrev }}$ represents the voltage drop due to several irreversible loss mechanisms, which causes the theoretical FC voltage drop. It is calculated as the sum of the activation voltage $V_{\text {act }}$, concentration voltage $V_{\text {conc }}$ and the ohmic voltage $V_{\text {ohmic }}$. A simple way to calculate them is described in $[10,15]$. The expressions used in this model are the following:

$$
\begin{aligned}
& V_{\text {act }}=\frac{R_{g} T}{2 F \alpha} \cdot \lg \left(\frac{i_{\text {den }}}{i_{0}}\right)(18) \\
& V_{\text {ohmic }}=R_{f c} \cdot i_{\text {den }} \\
& V_{\text {conc }}=\frac{R_{g} T}{2 F} \cdot \lg \left(1-\frac{i_{d e n}}{i_{\text {lim }}}\right)
\end{aligned}
$$

In the $\mathrm{CM}$, the irreversible voltage is calculated from more exact equations, which depend on other parameter, such as oxygen partial pressure, water saturation pressure and some constants determined empirically [3].

\subsubsection{Compressor Model}

The purpose of the compressor is to supply the inlet air mass flow to the cathode in order to maintain constant oxygen excess ratio $\lambda_{O 2}[3,16]$, equal to 2.5 in case of the commercial FC considered in this work. The oxygen excess ratio is defined as the ratio between the oxygen supplied and the oxygen used in the cathode.

$$
\lambda_{O 2}=\frac{q_{O 2}^{i n}}{q_{O 2}^{r}}
$$


If the relative humidity is assumed to be $100 \%$, the oxygen excess ratio is related with the air flow through the following equation:

$W_{\text {air flow }}=\left(1+\frac{M_{v} \cdot p_{\text {sat }}\left(T_{\text {atm }}\right)}{M_{a} \cdot\left[p_{\text {atm }}-p_{\text {sat }}\left(T_{\text {atm }}\right)\right]}\right) \cdot \frac{1}{x_{02}} \cdot \lambda_{O 2} \cdot M_{O 2} \frac{N \cdot I_{F C}}{4 \cdot F}$

where the saturation pressure $p_{\text {sat }}$ is a function of the atmospheric temperature.

In case of the $\mathrm{CM}$, the air mass flow rate is determined from a compressor flow map, and a nonlinear curve method is used to model the compressor characteristics. Finally, the compressor modelling is performed in both models from the power required to drive compressor, motor torque of DC motor and compressor speed from the equilibrium torque equation or $2^{\text {nd }}$ Newton's law, such as described in [3].

\subsection{Reduced Model 2}

This second reduced model (reduced model 2, RM2) is based on one of the most model used for hybrid vehicles and portable applications [5--8], which presents a more reduced order than the previous one. Figure 4 depicts the configuration of this reduced model.

In this case, the models of the anode and cathode are very similar to the previous one. In fact, the partial pressures of the hydrogen and oxygen are calculated in a similar manner.

In this model, the hydrogen output flow $q_{\mathrm{H} 2}{ }^{\text {out }}$ is calculated from the relation between the molar flow of hydrogen and its partial pressure inside the channel $[6,7,14]$.

$q_{H 2}^{\text {out }}=K_{H 2} \cdot p_{H 2} \quad$ (23)

where $K_{H 2}$ is considered to be the average value of the ratio between the output hydrogen flow and the hydrogen partial pressure obtained with the RM1.

Considering Eq. (23) and applying the Laplace transformation to Eq. (1), it is obtained the following expression for the hydrogen partial pressure:

$$
\begin{gathered}
p_{H 2}=\frac{1 / K_{H 2}}{1+\tau_{H 2} S}\left(q_{H 2}^{i n}-q_{H 2}^{r}\right) \\
\tau_{H 2}=V_{a n} /\left(K_{H 2} R_{g} T\right)
\end{gathered}
$$

where $\tau_{H 2}$, expressed in seconds, is the value of the system pole associated with the hydrogen flow.

A similar procedure can be applied to determine the oxygen partial pressure. Considering Eq. (11) and applying the Laplace transformation to Eq. (8), the following expression can be derived for the oxygen partial pressure:

$$
\begin{gathered}
p_{O 2}=\frac{1 / K_{O 2}}{1+\tau_{O 2} S}\left(q_{O 2}^{i n}-q_{O 2}^{r}\right) \\
\tau_{O 2}=V_{c a t} /\left(K_{O 2} R_{g} T\right)
\end{gathered}
$$

where $\tau_{O 2}$, expressed in seconds, is the value of the system pole associated with the oxygen flow, and $K_{O 2}$ is the same constant used for the RM1.

In this model, it is assumed that the anode and cathode present the same constant pressure so that it is not needed to use Eqs. (12) and (13) to calculate the anode and cathode pressures, as performed in the RM1.

Apart of this, other differences with respect to the RM1 appear in the way of calculating the FC voltage and in the modelling of compressor and hydrogen input valve.

As it will be shown in the simulations, the concentration voltage drop is not very high when the FC current density is small. Assuming that the PEM FC will not work at high current density, the concentration voltage drop is ignored in this reduced model. Therefore, the FC voltage model is similar to the model described for the RM1, except for Eq. (20) which is not used in this model.

The other two differences are due to the ideal modelling of compressor and hydrogen input valve. In case of the compressor, it has been removed so that the power demanded by the compressor is not considered in the FC system. With this simplification, the incoming oxygen to the cathode is determined from Eq. (21) assuming a constant oxygen excess ratio of 2.5.

By the same way, the incoming hydrogen valve model has been removed. In this case, the hydrogen input flow is derived from Eq. (4) and the hydrogen valve flow is calculated from Eq. (7) considering a global utilisation factor near to the unit. 


\section{Hybrid System for the Tramway}

The purposed hybrid system for the tramway is composed of: 1) PEMFC system; 2) battery; 3) dc/dc boost converter; 4) loads: tramway traction system and auxiliary services; 5) braking chopper; and 6) EMS. Figure 5 shows the configuration of hybrid system for the tramway.

The FC is the primary energy source of tramway. It is connected to a dc/dc boost converter which raises the low dc voltage delivered by the FC to the traction standard dc bus.

A rechargeable battery is used as electrical energy storage unit to supplement the output of the FC during tramway acceleration and cruise and for energy recovery during braking. It has been sized so that it store sufficient energy and provide adequate peak power for the tramway to have a specified acceleration performance and the capability to meet appropriate driving cycle.

The tramway loads supplied from the two energy sources are the auxiliary services and the traction system. The auxiliary services module represents the power consumption due to the tramway auxiliary equipment (lighting, fans, steering air conditioning systems...). The tramway traction system represents the power consumption due to the traction electric wheel motors.

Finally, the EMS determines the reference signals for the FC and the dc/dc boost converter in order to distribute accurately the power from the two electrical sources. In addition, it determines the reference signal for energy dissipation in the braking chopper when required during regenerative braking.

\subsection{Battery}

Many battery systems have been experimented for hybrid vehicles (transit buses, light trucks and tramways), using Pb-Acid, Ni-Cd or Ni-MH. Practical experience shows that Ni-MH, in spite of its higher cost, is the most suitable system in terms of endurance and reliability [17]. Although Ni-MH batteries will be gradually replaced by Li-Ion batteries in future due to their better performance, they are currently much more expensive. For this reason, a Ni-MH battery has been selected for the tramway hybrid system developed in this work. The battery specifications are: $34 \mathrm{Ah}, 756 \mathrm{~V}$ Ni-MH battery with an overall rated power of $260 \mathrm{~kW}$ and a peak power of $350 \mathrm{~kW}$. It has been modelled by the Ni-MH battery model included in SimPowerSystems toolbox of Simulink® [18].

$$
\begin{aligned}
& U_{b a t}=E_{b a t}-R_{i} \cdot I_{b a t} \\
& E_{b a t}=E_{o}-K_{p} \cdot \frac{Q}{Q-\int i \cdot d t}+A \cdot \exp \left(B \cdot \int i \cdot d t\right)
\end{aligned}
$$

In transportation application using Ni-MH batteries, it is preferably kept the stage-of-charge (SOC) as close to $50 \%$ as possible; or within 30 to $70 \%$. Since at these states-of-charge, the coulombic charge efficiency is very high [19]. These operating recommendations for the battery have been considered in EMS design. In fact, the implemented model calculates the battery SOC as [18]:

$$
\operatorname{SOC}(\%)=100 \cdot\left(1-\frac{\int i \cdot d t}{Q}\right)
$$

\subsection{Boost Converter}

A classical dc/dc boost converter $[20,21]$ is selected as FC power converter, which adapts the dc voltage supplied by the FC, $235 \mathrm{~V}$ at its rated power, to the $750 \mathrm{~V}$ traction standard dc bus.

The boost converter is composed of a high frequency inductor $L_{l}$, an output filtering capacitor $C_{1}$, a diode $D_{l}$, and a main switch $S_{l}$. Switch $S_{2}$ is a shutdown device for test security to prevent the FC stack from short circuits in case of accidental destruction of $S_{l}$, or faulty operation of the regulator. The boost converter is based on the current control loop. An appropriate control of the fraction of time that the converter is conducting (duty cycle) allows the FC current control. Acting on the switch $S_{l}$ gate signal, it is therefore possible to determine the distribution of the power load between the two energy sources, FC and battery.

\subsection{Tramway loads}

As mentioned previously, the tramway loads are the auxiliary services and the traction system. In this work, both loads have been modelled as controlled dc current source connected to the dc bus, whose 
current is a function of the power consumption and the dc bus voltage.

\subsection{Braking Chopper}

In regenerative braking, some of the kinetic energy is converted into electrical energy and stored in the battery, in order to be used during the next acceleration, or whenever else needed. However, part of the regenerative braking energy must be dissipated in the braking resistor when it cannot be absorbed by the battery due to its limitations.

The braking chopper absorbs the energy produced by tramway deceleration when required. It has been modelled by a current source parallel with the dc bus. In this case, the control system determines the effective resistance to be required to dissipate the power, and thus the current is calculated from the dc bus voltage and the effective resistance.

\section{Energy Management System}

The goal of this paper is to perform a comparative study of PEMFC models and to choose the most appropriate for its integration in the modelling of the hybrid propulsion system of a tramway. It has been developed a model of all the main components of the hybrid tramway. The models are evaluated when integrated into a FC-battery powered hybrid system.

Note that the FC has a slow dynamic response due to the air compressor dynamic and the electromechanical dynamic inside the FC. In fact, the commercial FC used in this work can reach a quick power change (from 10\% to $90 \%$ rated power) at less than 2 seconds. When the FC cannot reach the reference power during a quick power change (such as acceleration) due to its slow dynamic response, it is required the support of battery to provide fast, additional power and to improve the transient response. On the other hand, the battery enables the recovery and storage of regenerative braking energy, and thus the reduction of the size of the FC and the increase of the system efficiency. Furthermore, the braking chopper must operate to dissipate regenerative braking energy when it cannot be absorbed by the battery due to its limitations.

The aim of tramway EMS is to provide the power needed by optimizing the energy generated by the system and ordering the operation of the braking resistor, when necessary, during regenerative braking. Following this objective, a new control strategy is presented. It combines a state machine control strategy based on eight states and a cascade control structure composed of two control loops. It has been applied to evaluate the configuration, modelling and energy management of the power sources adopted for the tramway.

\subsection{State Machine Control Strategy}

State machine control strategy is based on eight states in order to decide the operating point for each component of hybrid system. It generates the reference power for FC and battery and the power to be dissipated in the braking resistor. Furthermore, this control tries to avoid continuous changes in FC reference power, since the FC dynamic response is slow. Thus, the changes in the reference power will occur when the hybrid system components reach their limitation.

In this control strategy, the following values were considered:

- The maximum and minimum powers which the FC can generate $\left(P_{f c}^{\max }, P_{f c}{ }^{m i n}\right)$, and the optimum FC power $\left(P_{f_{c}}^{o p t}\right)$, which corresponds to the maximum efficiency power of the FC.

- The maximum charge power $\left(P_{b a t c h a r}{ }^{\max }\right)$ and maximum discharge power $\left(P_{\text {bat disc }}{ }^{\max }\right)$ of the battery.

- The maximum and minimum battery SOC (SOC $\left.C^{\text {max }}, S O C^{\text {min }}\right)$.

In order to avoid startup problems, an 'always on' strategy is applied to the FC [22, 23]. The minimum power consumed by the tramway during the driving cycle is that of the auxiliary services (61 $\mathrm{kW}$ ), which is the only power consumed during the stops. Therefore, it was selected as the minimum power generated by the $\mathrm{FC}, P_{f c}{ }^{m i n}$. This value is close to the optimum FC power $(80 \mathrm{~kW})$. In addition, two operation modes were considered for the FC. The FC can operate at constant power (load levelling strategy) or by adapting the power generated to the load demanded (load following strategy).

The state machine control determines the operational state according to the demanded load, the tramway speed and the battery SOC. Three levels were considered for the battery SOC: High SOC (60\%$65 \%)$, normal SOC (50\%-60\%) and low SOC (45\%-50\%). Two hysteresis cycles, as shown in Figure 6, are used for the changes among these levels. Next, the eight states considered in the control strategy are detailed. 
- State 1: High SOC and $P_{\text {load }}<P_{f_{c}}^{\text {opt }}$. The hybrid system adopts this state when the battery SOC is high and the power demanded by the tramway is less than the optimum FC power. In this state, the FC operates at minimum power, providing the auxiliary services power when the tramway is stopped. The FC is made to operate at optimum power instead of minimum power in order to improve the FC efficiency during the driving cycle. Because of the slow response of the FC, the battery must supplement the output of the FC to provide the load power, when necessary, during tramway acceleration.

- State 2: High SOC and $P_{f c}^{o p t} \leq P_{\text {load }} \leq 190$. In this state, the FC operates with a load following strategy, and the battery must supplement the output of the FC, when necessary. Because the maximum power demanded by the tramway is about $540 \mathrm{~kW}$, the FC should provide $190 \mathrm{~kW}$ if the battery is made to operate at its maximum discharge power $(350 \mathrm{~kW})$. In this case, the FC provides an output power between its optimum power and $190 \mathrm{~kW}$.

- State 3: High SOC and $P_{\text {load }}>190$. When the power demanded by the tramway is greater than 190 $\mathrm{kW}$, the FC operates with a load levelling strategy, providing $190 \mathrm{~kW}$. When the tramway requires more power, it is provided by the battery. In fact, it may be necessary for the battery to provide its maximum discharge power in order to supplement the FC in order to supply the maximum power demanded by the tramway.

- State 4: Normal SOC and $P_{\text {load }}<P_{f_{c}}{ }^{\text {opt }}$. In this state, the hybrid system works the same as in state 1. The FC operates at minimum power, providing the auxiliary services power when the tramway is stopped. When the tramway is running, the FC generates its optimum power.

- State 5: Normal SOC and $P_{f c}^{\text {opt }} \leq P_{\text {load }} \leq P_{f_{c}}{ }^{\max }$. The FC operates with a load following strategy and the battery supplements the FC output, when necessary, during tramway acceleration.

- State 6: Normal SOC and $P_{\text {load }}>P_{f c}^{\max }$. In this case, the FC operates at maximum power and the battery supplements the necessary power to cover the load demand.

- State 7: Low SOC and Speed=0. When the tramway is stopped and the battery SOC is low, the FC is demanded to generate its maximum power. In this state, the FC supplies the auxiliary services (61 $\mathrm{kW}$ ) and it charges the battery (with a power of $139 \mathrm{~kW}$ ), and in this way, the battery could rapidly achieve normal SOC.

- State 8: Low SOC and Speed>0. In this state, the FC must generate the demanded load plus extra power that will charge the battery, whenever possible. The battery is required to supplement the output of the FC, when necessary, during tramway acceleration.

During regenerative braking, the battery will be charged for energy recovery. However, in order to avoid excessive charging, the braking resistor dissipates energy whenever the battery reaches its operating limits.

\subsection{Cascade Control Structure}

This control allows FC and battery to achieve the operating points determined by the state machine control strategy according to the operating state. This cascade control is composed of two control loops, as shown in Figure 7. The outer loop controls the battery power and the inner one controls the FC generating current.

- Outer Loop Control: As mentioned previously, the control strategy generates the reference power for the battery. From the error between the battery reference power and the actual power, a PI controller generates the FC system net reference power. This power must be limited in slope and in level according to the FC system characteristic and after that with the actual FC voltage is calculated the FC reference current for the inner control loops. This current is limited according to the maximum and minimum currents that FC can generate before being compared with the actual current.

- Inner Loop Control: In this control loop, a PI controller is used to determine the duty cycle of dc/dc boost through the error between the FC current reference and the actual output current. By this way, FC can generate the reference power obtained from the outer loop control.

\section{Simulations Results}

The two reduced models of PEM FC presented in this paper, the reduced model 1 (RM1) and reduced model (RM2), are evaluated in their application to the hybrid propulsion system for a real surface tramway by means of simulations, where the response of the reduced models are compared with that one of complete model (CM). With this objective, steady-state and dynamic simulations have been performed implemented in MATLAB-Simulink®. 


\subsection{Steady-state Simulations}

From the steady-state simulations, two FC characteristic curves have been represented in order to compare the models: 1) the FC polarisation curve (voltage versus current density) in Figure 8a; and 2) the FC power curve (output power versus current density) in Figure 8b. In Figure 8b, it has been represented: 1) the output net power supplied by the two FCs, $P_{F C T}$, which is calculated as the difference between the total power generated by the two $\mathrm{FC}$ and the power consumed by the compressors in order to impulse air to cathode; and 2) the total power generated by a FC without considering the power consumed by the compressor, $P_{\text {stack }}$. As explained previously, the compressor has been considered ideal in the RM2 so that the $\mathrm{FC}$ output power has been calculated ignoring the power consumed by the compressor.

Figure 8a shows the FC polarisation curve obtained from each model. Note that the FC voltage depends on the voltage losses, and they vary with the current density. The polarisation curve obtained from the CM and RM1 present similar results than that shown by the commercial FC considered in this work [11]. Differences between the results of CM and RM1 are minimal from the connection of the stack to $0.95 \mathrm{~A} / \mathrm{cm}^{2}$ approximately, which corresponds to the common working region of the $\mathrm{FC}$. After that current density, differences between both curves increase a little, due to mainly the minimal effect of the concentration drop voltage, such as observed in Figure 9b. RM2 shows higher cell voltage and higher differences, particularly for high current density. It is mainly due to that the concentration voltage drop has been ignored in this model, and this voltage drop increases with the current density.

Similar results are obtained in the FC power curve, shown in Fig. 8b. When compared with the power curves obtained by the CM, the RM1 achieves a better approximation than the RM2. Thus, the highest differences in the FC power curve obtained from the RM2 appear with high current density, because the power consumed by the compressor has not been considered in this model.

As regards with the irreversible voltage, the results obtained from each model are similar, such as shown in Figure 9a. Nevertheless, little differences between the CM and RM1 can be observed from 0.5 $\mathrm{A} / \mathrm{cm}^{2}$, which are due to mainly the concentration voltage drop (Figure $9 \mathrm{~b}$ ). These differences are a little higher in case of the RM2, because they were ignored.

\subsection{Dynamic Simulations}

For dynamic simulations, the three models have been integrated in the described hybrid system, and the resulting models have been simulated for the real drive cycle of the Metro Centro tramway, which serves the centre of Seville, a city in Spain.

The tramway follows a symmetrical route of going and return, which last $660 \mathrm{~s}$. Only $330 \mathrm{~s}$ have been simulated which corresponds to half of the drive cycle or to the outward route. Figure 10 shows the speed and the mechanical power required by the tramway during this route. The cycle followed by the tramway is basically composed of four trips and four stops. The first one lasts about $12 \mathrm{~s}$. It consists of an acceleration and deceleration, reaching the tramway a maximum speed of $20 \mathrm{~km} / \mathrm{h}$. The following two trips are very similar. Both of them last about $60 \mathrm{~s}$, and include accelerations and decelerations. However, these trips show little differences in the maximum speed and speed changes. The three first stops endure the same time, about $15 \mathrm{~s}$. The fourth trip is completely different. It is the longest, about $120 \mathrm{~s}$. In this case, the tramway maintains a constant speed of $15 \mathrm{~km} / \mathrm{h}$ along the whole trip. Besides, the fourth stop time is higher, about $60 \mathrm{~s}$.

To check the performance of the state control with normal and high battery SOC along the performed simulation, an initial battery SOC of $65 \%$ was considered. This corresponds to a high SOC. Figure 11 shows the operational states and battery SOC obtained from the models along the simulations. It can be observed that the three models operate with the same operational states during all the simulation. During the first seventy seconds, the battery SOC is high so that the system adopts the states 1,2 and 3. From the seventy second to the end of the simulation, the system operates with the states 4,5 and 6 because of the battery SOC is normal.

Figures 12, 13, 14 and 15 depict the internal behaviour of FC system during the driving cycle. In Figure 12, the hydrogen and oxygen partial pressures are depicted. As it can be observed, the approximation of the partial pressures is good enough in case of RM1and but only for the hydrogen partial pressure in case of RM2, because the oxygen partial pressure obtained with RM2 presents greater differences with respect to the response of CM. The anode and cathode pressures are shown in Figure 13. In this case, good results are obtained again, even though a maximum error around of $10 \%$ is obtained with the RM1, which demonstrates the right approximations performed in Eqs. (12) and (13). For both the total FC current and output FC voltage (Fig. 14), RM2 presents higher differences with respect to CM. 
Finally, for a better understanding of the behaviour of each FC model, the hydrogen entering, fuel cell system efficiency and utilization factor are represented in Figure 15. The entering hydrogen is calculated from the upstream valve hydrogen flow.

$$
M_{H 2 \text { con }}=N_{f c} \int_{\text {cycle }} q_{H 2}^{\text {valve }} d t
$$

On the other hand, the FC system efficiency is obtained by the next equation [24].

$$
\eta_{F C S}=\frac{\int_{\text {cycle }} P_{F C T} d t}{N_{f c} \cdot \int_{\text {cycle }} P_{H 2} d t}
$$

where and $P_{F C T}$ is the output net power supplied by the two FC systems considered in the hybrid tramway and $P_{H_{2}}$ is the theoretical power associated with the hydrogen, which is expressed as

$$
P_{H 2}=\frac{P_{F C}+P_{\text {com }}}{\eta_{\text {therm }} \cdot U_{f g} \cdot \eta_{\text {stack }}}=\frac{P_{\text {stack }}}{\eta_{\text {therm }} \cdot U_{f g} \cdot \eta_{\text {stack }}}
$$

where $P_{F C}$ is the output net power supplied by a FC system, $P_{c o m}$ is the power consumed by the compressor, $\eta_{\text {therm }}$ is the thermodynamic efficiency defined by the ratio of $\Delta G_{f}$ to $\Delta H_{f}$, and $\eta_{\text {stack }}$ can be calculated as the relationship between the cell voltage $V_{\text {cell }}$ and the standard-state reversible voltage $E_{\text {cell }}^{0}$.

Final mass hydrogen consumed by the FC system during the route is similar in case of CM and RM1, with a total mass consuming around of $0.46 \mathrm{~kg}$. However, RM2 presents a lower final mass hydrogen consume, around of $0.42 \mathrm{~kg}$, because, in this model, FC does not has to generate energy for any compressor. In case of FC efficiency, CM presents an average value around of $55 \%$ along the simulation. As it can be seen, RM1 achieves a better approximation of FC efficiency than RM2, which shows higher efficiency due to the removal of the compressor. As regard the utilization factor, RM1 obtains similar results to $\mathrm{CM}$, an average value around of $33 \%$ along the simulation.

Figure 16 and 17 show the performance of hybrid system for driving cycle, where the powers of each one of the components of hybrid system (FC, battery, loads and braking chopper) are represented. Note that $\mathrm{FC}$ cannot reach the reference power during a quick power changes due to its slow dynamic response. When the tramway accelerates, it demands higher power, so that the FC tries to generate its maximum power and the battery supplements to FC producing the rest of power required by the tramway during the acceleration. In case of deceleration, it is produced regenerative braking (negative load power), so that part of regenerative power is used to charge the battery (which is limited to its maximum value) and the rest one is dissipated in the braking resistor when the battery achieves its maximum charge power.

As it can be observed in the results obtained by the two reduced models, when representing the external behaviour of FC integrated in the hybrid system of tramway (Figs. 16 and 17), are similar to those ones obtained by $\mathrm{CM}$, but with an important reduction of computation time. For RM1, the reduction of computation time with respect to $\mathrm{CM}$ is around of $30 \%$, whereas RM2 presents a greater reduction, around of $42 \%$.

When compared with CM, RM1 model obtains better results than RM2 in order to represent both the internal and external behaviour of a FC integrated in hybrid system. RM2 allows approximating the power delivered by the FC to the hybrid system, and therefore, simulating the performance of tramway hybrid. However, this model presents noticeable differences in the FC operating variables, such as partial pressures, output voltage and current, and efficiency.

\section{Conclusions}

This paper has presented a comparative study of PEM FC models for integration in hybrid propulsion systems of urban public transport. A new reduced model is proposed and compared with one of most used reduced model for hybrid vehicles and portable applications. These models were evaluated in a FCbattery powered hybrid system for a surface tramway by comparing the simulated responses with that one 
of a complete model (CM), which includes a detailed dynamic model of the main components of FC system.

The first reduced model (RM1), a new model proposed in this work, was derived from applying the following simplifications to the CM:

- The gases are considered ideal.

- The FC is fed with hydrogen and air.

- The electrode channels are small enough so that the pressure drop across them is negligible.

- The ratio of pressures between the inside and outside of the electrode channels is large enough to assume choked flow.

- Assuming that inlet oxygen and hydrogen coming respectively from compressor and tank present a stable mass flow, the supply manifolds have been eliminated.

- Return manifolds have been removed since the outlet flow of any gas is considered to be proportional to its partial pressure inside the channel.

- The humidifier and air cooler are considered ideal so that the FC operates at optimum temperature $\left(80^{\circ} \mathrm{C}\right)$ and with constant relative humidity.

- The compressor is modelled by a first order system in order to approximate its dynamic response.

The second reduced model (RM2) is based on one of the most used models for hybrid vehicles and portable applications. To obtain this reduced model, the following simplifications were applied to the RM1:

- The concentration voltage drop was eliminated, and therefore it was not considered in the FC output voltage.

- The compressor was considered ideal so that the power demanded by the compressor was ignored.

- The input hydrogen valve was also considered ideal so that it was removed from the model, and the incoming hydrogen flow was calculated from the global utilization factor.

- It was assumed that the anode and cathode presented the same constant pressure.

Steady state and dynamic simulations were performed for comparison of the models. In the steady state simulations, the FC polarisation and power curves were represented. In case of FC polarisation curve, the curve obtained from each model was compared with the real curve of the commercial FC from Nuvera considered in this work. In the dynamic simulations, the models were integrated in the tramway hybrid system and simulated for the real drive cycle of the tramway. The drive cycle and the demanded load used in the dynamic simulations correspond to the tramway that actually serves the centre of Seville, a city in Spain.

From the performed simulations, interesting conclusions were obtained. When compared the performance of the FC integrated in the tramway hybrid (powers at FC, battery, braking resistor and load), both reduced models show similar results with an important reduction of computation time with respect to the CM (reduction of $30 \%$ for RM1 and $42 \%$ for RM2). When compared the FC operating variables, RM1 model obtained better results than RM2, since RM2 shows noticeable differences in partial pressures, voltage, current and efficiency. These differences are due to that the concentration voltage drop and power consumed by compressor were ignored, and the hydrogen valve was considered ideal.

RM1achieves a suitable equilibrium between approximation of FC response and computational time, and therefore, it can be concluded that it results to be the most appropriate FC model for propulsion system applications from those studied in this work.

\section{Acknowledgement}

This work was supported in part by Hynergreen Technologies S.A. and by the Cenit Program from the Centre for the Development of Industrial Technology, Spanish Ministry of Science and Technology, under the Ecotrans research project. A national industries consortium, leaded by CAF ('Construcciones $y$ Auxiliar de Ferrocarriles'), and to which belongs Hynergreen Technologies, is working in this project for the development of ecological technologies for urban transport.

\section{List of Symbols}

Fuel cell system

$\alpha \quad$ charge transfer coefficient (-)

$E_{\text {cell }}^{0} \quad$ Standard-state reversible voltage $(V)$ 
Battery A

Nernst's instantaneous voltage $(V)$

Faraday`s constant ( $\mathrm{C} / \mathrm{mol}$ )

FC current $(A)$ current density $\left(A / \mathrm{cm}^{2} / \mathrm{mA} / \mathrm{cm}^{2}\right)$ reaction exchange current density $\left(A / \mathrm{cm}^{2} / \mathrm{mA} / \mathrm{cm}^{2}\right)$ maximum current density $\left(A / \mathrm{cm}^{2} / \mathrm{mA} / \mathrm{cm}^{2}\right)$ hydrogen valve molar constant $\left(\mathrm{kg} \cdot \mathrm{s}^{-1} . \mathrm{bar} \mathrm{r}^{-1}\right)$ oxygen valve molar constant $\left(\mathrm{kg}^{-1} \mathrm{~s}^{-1} . \mathrm{bar}^{-1}\right)$

$\mathrm{N}_{2} / \mathrm{O}_{2}$ proportional pressure constant (-)

empirical constant in calculating (in volts per Kelvin). upstream hydrogen valve constant $\left(\mathrm{kg} . \mathrm{s}^{-1} / \mathrm{cm}^{2}\right)$ dry air molar mass $\left(\mathrm{kg}^{\mathrm{m}} \mathrm{mol}^{-1}\right)$ molar mass of hydrogen $\left(\mathrm{kg}^{\mathrm{m}} \mathrm{mol}^{-1}\right)$ molar mass of oxygen $\left(\mathrm{kg} . \mathrm{mol}^{-1}\right)$ water molar mass $\left({\left.\mathrm{kg} . \mathrm{mol}^{-1}\right)}^{-1}\right.$ number of cells (-)

total pressure in the anode $(\mathrm{bar} / \mathrm{Pa})$ total pressure in the cathode $(\mathrm{bar} / \mathrm{Pa})$ hydrogen partial pressure $(\mathrm{bar} / \mathrm{Pa})$ nitrogen partial pressure $(\mathrm{bar} / \mathrm{Pa})$ oxygen partial pressure $(\mathrm{bar} / \mathrm{Pa})$ water partial pressure $(\mathrm{bar} / \mathrm{Pa})$ saturation pressure $(\mathrm{bar} / \mathrm{Pa})$ hydrogen flow recovered from the anode $\left(\mathrm{kg} . \mathrm{s}^{-1}\right)$ hydrogen input flow $\left(\mathrm{kg} . \mathrm{s}^{-1}\right)$ hydrogen output flow $\left(\mathrm{kg}^{\mathrm{s}} \mathrm{s}^{-1}\right)$ hydrogen flow that reacts $\left(\mathrm{kg} . \mathrm{s}^{-1}\right)$ hydrogen upstream valve flow $\left(\mathrm{kg} . \mathrm{s}^{-1}\right)$ oxygen input flow $\left(k g . s^{-1}\right)$ oxygen output flow $\left(\mathrm{kg} \cdot \mathrm{s}^{-1}\right)$ oxygen flow that reacts $\left(\mathrm{kg} . \mathrm{s}^{-1}\right)$ FC internal resistance $\left(\Omega \mathrm{cm}^{2}\right)$ hydrogen gas constant $\left(J . \mathrm{kg}^{-1} \cdot K^{-1}\right)$ oxygen gas constant $\left(J \cdot \mathrm{kg}^{-1} \cdot K^{-1}\right)$ ideal gas constant $\left(J . \mathrm{kg}^{-1} . K^{-1}\right)$ upstream open section valve $\left(\mathrm{cm}^{2}\right)$ FC absolute temperature $\left({ }^{\circ} K\right)$ ambient absolute temperature $\left({ }^{o} K\right)$ response time for hydrogen flow $(s)$ actual utilization factor of hydrogen (-) global utilization factor of hydrogen (-) reference utilization factor of hydrogen (-) volume of anode $\left(\mathrm{m}^{3}\right)$.

volume of cathode $\left(\mathrm{m}^{3}\right)$. activation over voltage $(V)$ cell voltage $(V)$ concentration over voltage $(V)$ fuel cell output voltage $(V)$ irreversible voltage or the loss voltage $(V)$ ohmic over voltage $(V)$ inlet air flow $\left(\mathrm{kg} . \mathrm{s}^{-1}\right)$ oxygen mass fraction in air (-) oxygen excess ratio (-)

exponential voltage $(V)$ exponential capacity $\left(A^{-1} \cdot h^{-1}\right)$ no load battery voltage $(V)$ 
constant voltage $(V)$

$I_{\text {bat }} \quad$ battery current $(A)$

$K_{p} \quad$ polarisation voltage $(V)$

$Q \quad$ battery capacity (A.h)

$R_{i} \quad$ internal resistance $(\Omega)$

$U_{\text {bat }} \quad$ battery voltage $(V)$

Energy management system

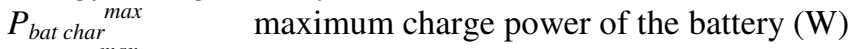

$P_{\text {bat disc }}{ }^{\max } \quad$ maximum discharge power of the battery (W)

$P_{b a t} \quad$ battery power $(W)$

$P_{b r} \quad$ power dissipated in the braking resistor $(W)$

$P_{f_{c}} \quad$ FC power $(W)$

$P_{f c} \max \quad$ maximum FC power $(W)$

$P_{f_{c}}{ }^{m i n} \quad$ minimum FC power $(W)$

$P_{f_{c}}{ }^{\text {opt }} \quad$ optimum FC power $(W)$

$P_{\text {load }} \quad$ tramway load demand $(W)$

SOC $C^{\max } \quad$ maximum $\operatorname{SOC}(\%)$

SOC $^{\text {min }} \quad$ minimum SOC $(\%)$

Simulations

$N_{f c} \quad$ number of individual FCs connected in parallel (-)

$M_{H 2 \text { con }} \quad$ hydrogen entering $(\mathrm{kg})$

$P_{c o m} \quad$ power demanded by the compressor $(W)$

$P_{F C} \quad$ FC output net power supplied by a FC system $(W)$

$P_{F C T} \quad$ FC output net power supplied by the two FC systems $(W)$

$P_{H 2} \quad$ theoretical power associated with the hydrogen $(W)$

$P_{\text {stack }} \quad$ FC total power without considering the power consumed by the compressor $(W)$

$\eta_{\text {stack }} \quad$ stack efficiency (-)

$\eta_{\text {therm }} \quad$ thermodynamic efficiency (-)

Models

CM FC complete model

RM1 $\quad$ FC reduced model 1

RM2 FC reduced model 2

\section{References}

[1] G. Hoogers, Fuel Cell Technology Handbook, CRC, Boca Raton, FL, 2003.

[2] S. M. Lukic, J. Cao, R. C. Bansal, F. Rodriguez, A. Emadi, IEEE Transactions on Industrial Electronics 2008, 55, 2258.

[3] J. T. Pukrushpan, H. Peng, A. G. Stefanopoulou, Control of fuel cell power system: Principles, modelling, analysis and feedback design. Springer, New York, 2004.

[4] S. Caux, J. Lachaize, M.Fadel, P. Shott, L. Nicod, Journal of Process Control 2005, 15, 481.

[5] F. Jurado, Fuel Cells 2004, 4, 378.

[6] M. Uzunoglu, M.S. Alam, Energy Conversion and Management 2007, 48, 1544.

[7] M. Y. El-Sharkh, N. S. Sisworahardjo, T. Yalcinoz. M. S. Alam, International Journal of Energy Research 2009.

[8] X. Li, L. Xu, J. Hua, X. Lin, J. Li, M. Ouyang, Journal of Power Sources 2009, 191, 542.

[9] A. Miotti, A. D. Domenico, Y. G. Guezennec, S. Rajagopalan, Proc. Vehicle Power and Propulsion (VPP'05) IEEE Conference, Chicago, USA, 2005, pp. 611.

[10] M. Uzunoglu, M.S. Alam, IEEE Transactions on Energy Conversion 2006, 21, 767.

[11] Nuvera, Andromeda PEM fuel cell, internet http://www.nuvera.com/.

[12] F. Barbir. PEM Fuel Cells Theory and Practice, Elsevier Inc.,2005

[13] W. H. Zhu, R. U. Payne, B. J. Tatarchuk, Journal of Power Sources 2006, 156, 512.

[14] J. Padulle's, G.W. Ault, J.R. McDonald, Journal of Power Sources 2000, 86, 495.

[15] C. Spiegel, PEM Fuel Cell Modeling and Simulation Using MATLAB, Academic Press, 2008.

[16] E. Hipp, S. Kerschl, T. Pflanz, and C. Gruber, Fuel Cells 2003, 3, 133. 
[17] M. Broussely, Industrial Applications of Batteries, Elsevier Science, Amsterdam, 2007.

[18] Hydro-Québec and MathWorks, Inc., SimPowerSystems ${ }^{\mathrm{TM}}$, Reference, Natick, MA, 2008.

[19] D. Linden, T. B. Reddy, Handbook of batteries, McGraw-Hill, NY, US, 2002.

[20] T. L. Skvarenina, The Power Electronics Handbook, CRC, Boca Raton, FL, 2002.

[21] R. M. Moore, S. Ramaswamy, J.M. Cunningham, K. H. Hauer, Fuel Cells $2006,5,387$.

[22] H. Y. Cho, W. Gao, H. L. Ginn, Proc. the 8'h Workshop on Power Electronics in Transportation (WPET 2004), Michigan, USA, 2004, pp. 159.

[23] D. Gao, Z. Jin, Q. Lu, Journal of Power Sources 2008, 185, 311.

[24] P. Corbo, F.E. Corcione, F. Migliardini, O. Veneri, Journal of Power Sources 2006, 157, 799.

\section{Figure Captions}

Fig. 1 Configuration of the PEM FC complete model.

Fig. 2 Configuration of the PEM FC reduced model 1.

Fig. 3 Control scheme for hydrogen input valve

Fig. 4 Configuration of the PEM FC reduced model 2.

Fig. 5 Configuration of the FC-battery hybrid system for the tramway.

Fig. 6 Hysteresis cycles for the battery SOC levels.

Fig. 7 Cascade control structure.

Fig. 8 (a) FC polarisation curve, and (b) FC power curve.

Fig. 9 (a) FC total irreversible voltage, and (b) FC concentration voltage drop.

Fig. 10 (a) Tramway speed, and (b) mechanical power.

Fig. 11 (a) Battery SOC, and (b) operational states.

Fig. 12 (a) Hydrogen partial pressure, and (b) oxygen partial pressure at FC.

Fig. 13 (a) Anode pressure, and (b) cathode pressure at FC.

Fig. 14 (a) Total FC current, and (b) FC output voltage.

Fig. 15 (a) Hydrogen mass entering, (b) FC efficiency and, (c) FC utilization factor.

Fig. 16 (a) FC output power, and (b) battery power.

Fig. 17 (a) Load power, and (b) power dissipated in the braking resistor. 


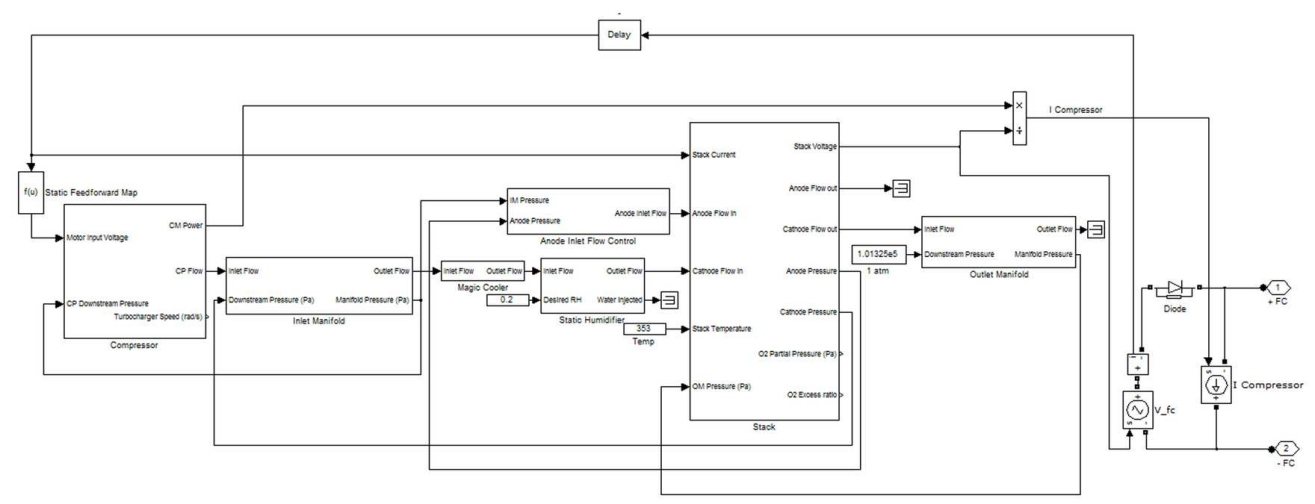

Fig. 1 Configuration of the PEM FC complete model. $73 \times 28 \mathrm{~mm}(600 \times 600$ DPI $)$ 


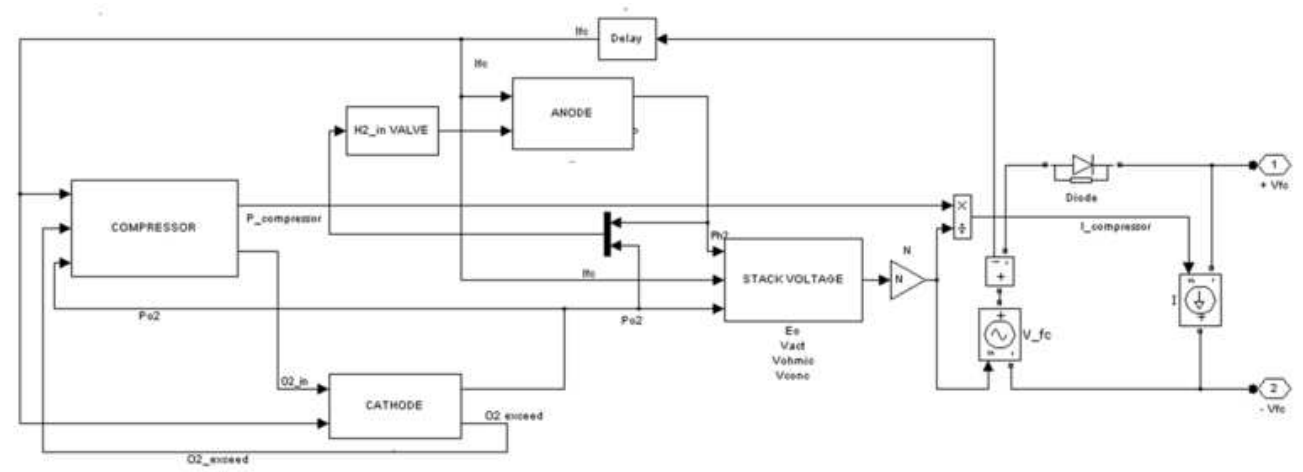

Fig. 2 Configuration of the PEM FC reduced model 1. $32 \times 11 \mathrm{~mm}(600 \times 600 \mathrm{DPI})$ 


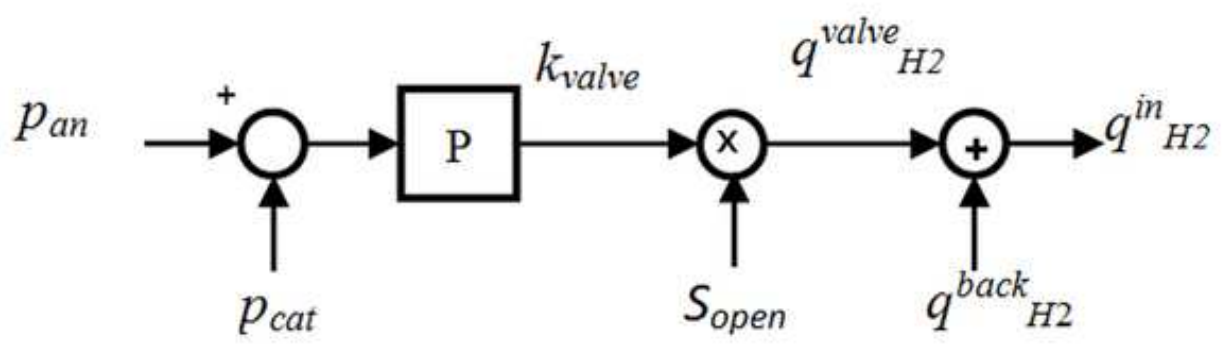

Fig. 3 Control scheme for hydrogen input valve. $25 \times 7 \mathrm{~mm}(600 \times 600 \mathrm{DPI})$ 


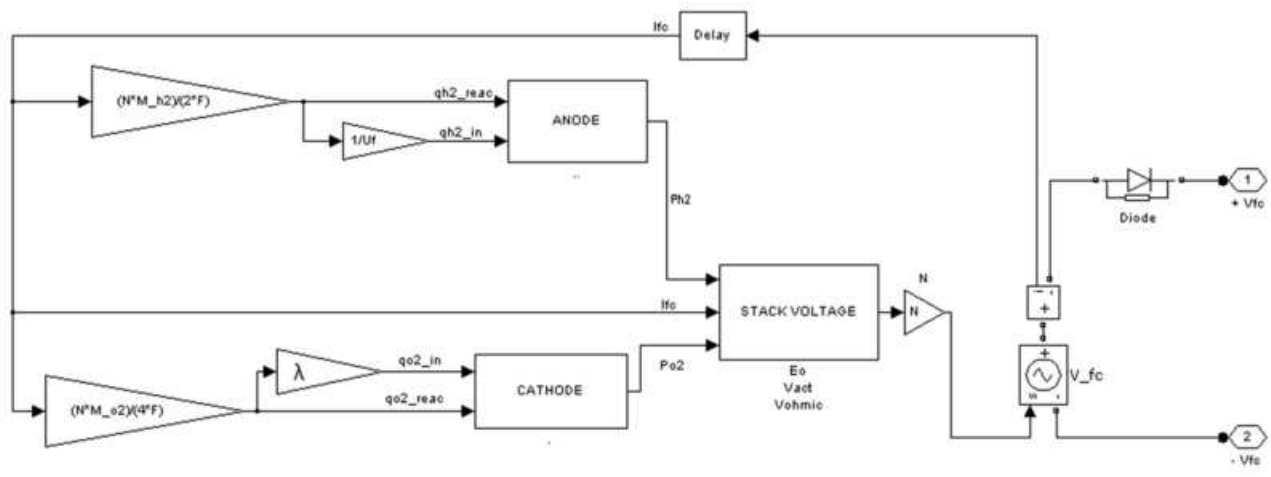

Fig. 4 Configuration of the PEM FC reduced model 2. $34 \times 13 \mathrm{~mm}(600 \times 600 \mathrm{DPI})$ 
8

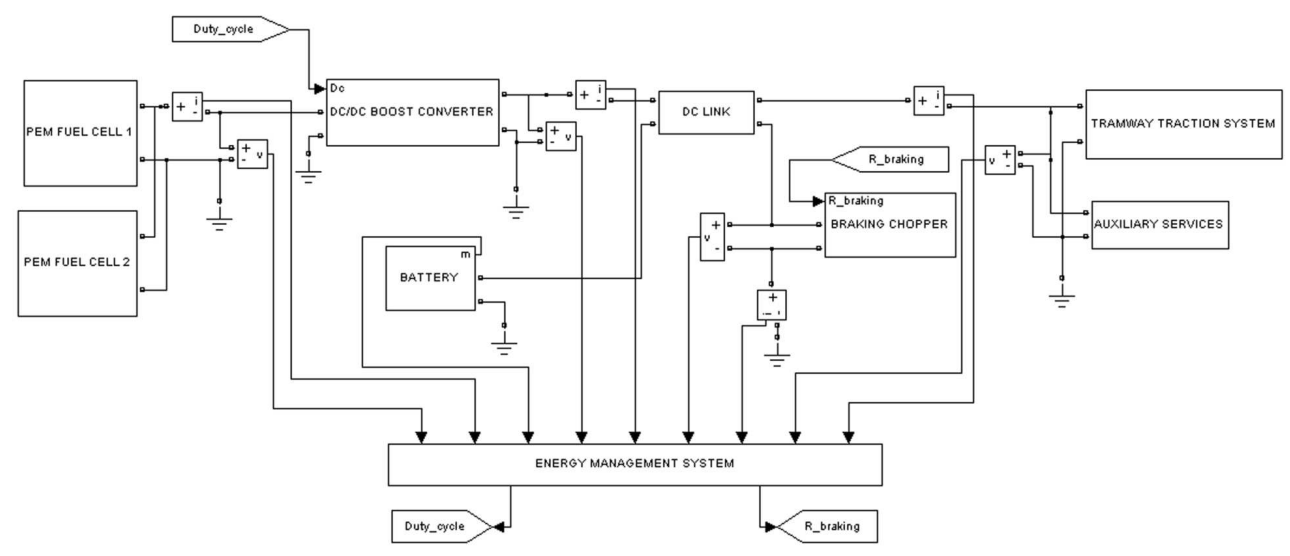

Fig. 5 Configuration of the FC-battery hybrid system for the tramway. $84 \times 37 \mathrm{~mm}(600 \times 600 \mathrm{DPI})$ 


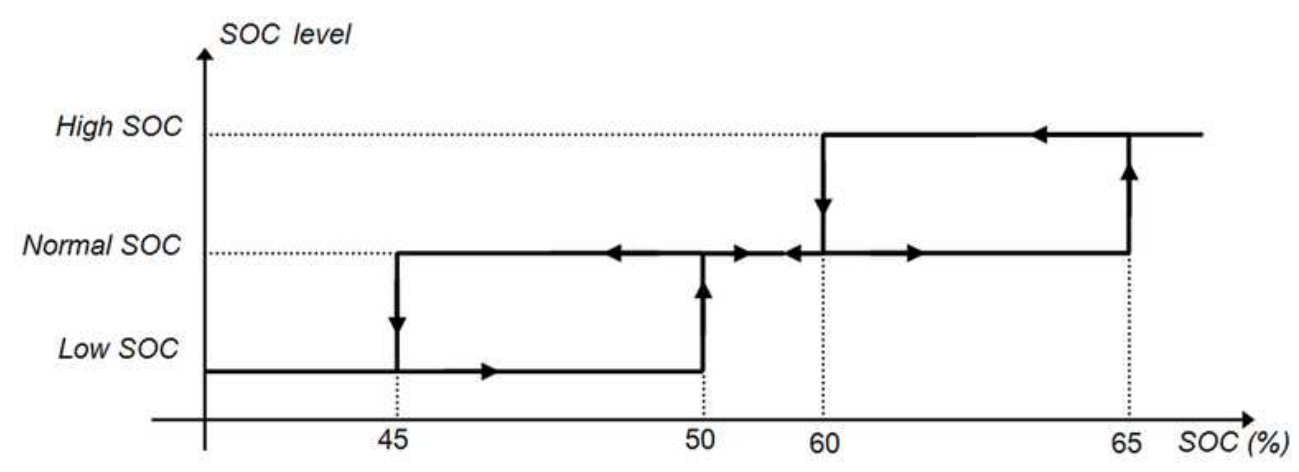

Fig. 6 Hysteresis cycles for the battery SOC levels. $33 \times 12 \mathrm{~mm}(600 \times 600 \mathrm{DPI})$ 


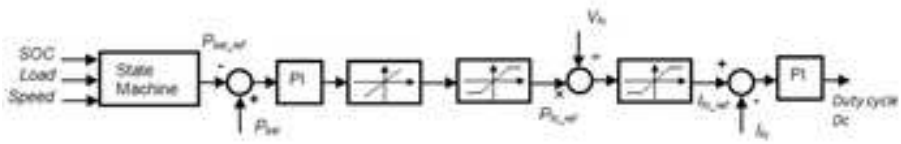

Fig. 7 Cascade control structure. $14 \times 2 \mathrm{~mm}(600 \times 600 \mathrm{DPI})$ 

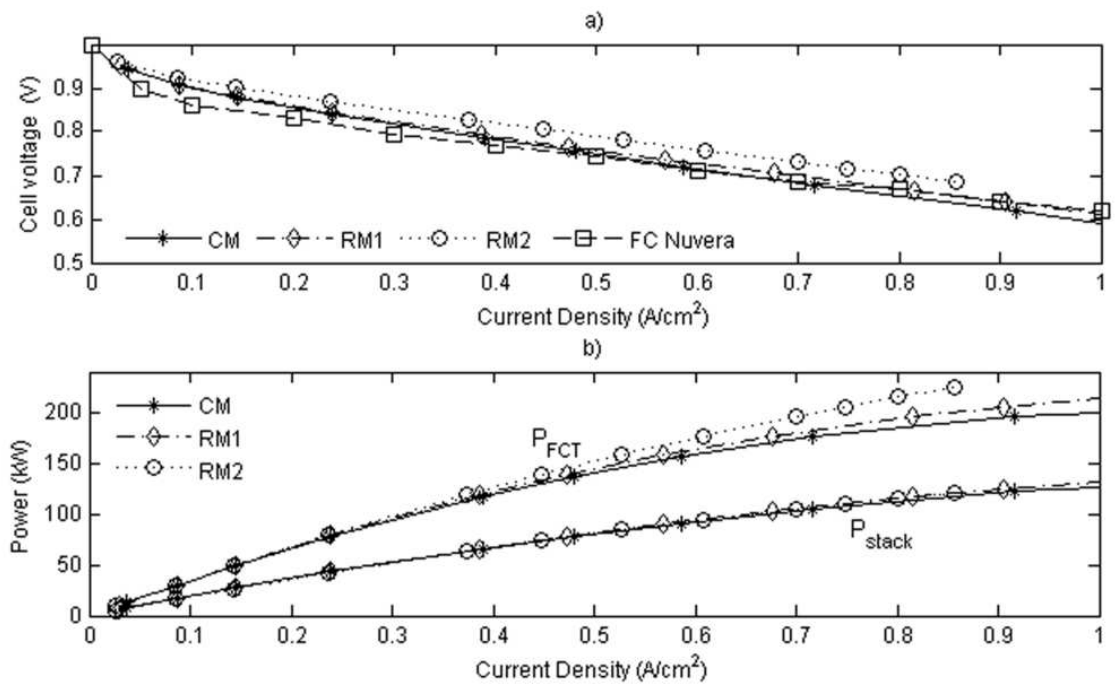

Fig. 8 (a) FC polarisation curve, and (b) FC power curve. $48 \times 26 \mathrm{~mm}(600 \times 600 \mathrm{DPI})$ 
Fig. 9 (a) FC total irreversible voltage, and (b) FC concentration voltage drop. $70 \times 55 \mathrm{~mm}(600 \times 600 \mathrm{DPI})$ 


1
2
3
4
5
6
7
8
9
10
11
12
13
14
15
16
17
18
19
20
21
22
23
24
25
26
27
28
29
30
31
32
33
34
35
36
37
38
39
40
41
42
43
44
45
46
47
48
49
50
51
52
53
54
55
56
57
59
60
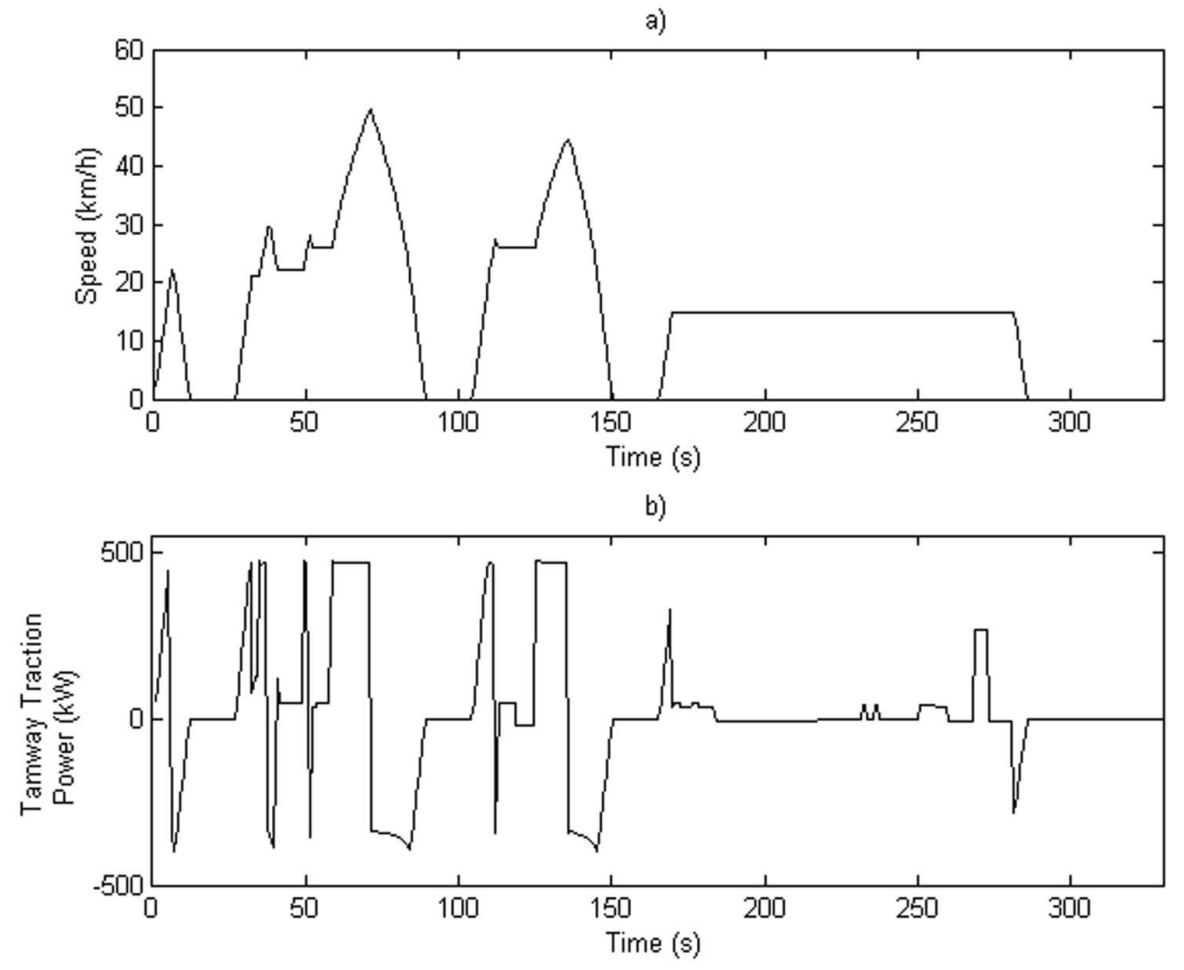

Fig. 10 (a) Tramway speed, and (b) mechanical power. $70 \times 55 \mathrm{~mm}(600 \times 600 \mathrm{DPI})$ 

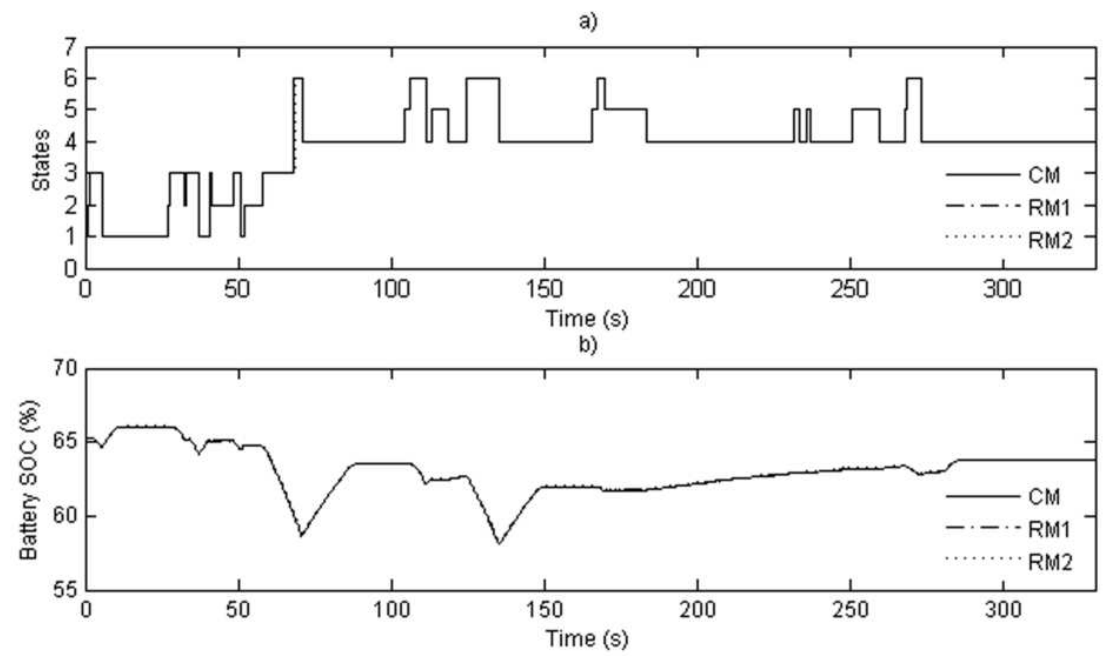

Fig. 11 (a) Battery SOC, and (b) operational states. $46 \times 24 \mathrm{~mm}(600 \times 600 \mathrm{DPI})$ 

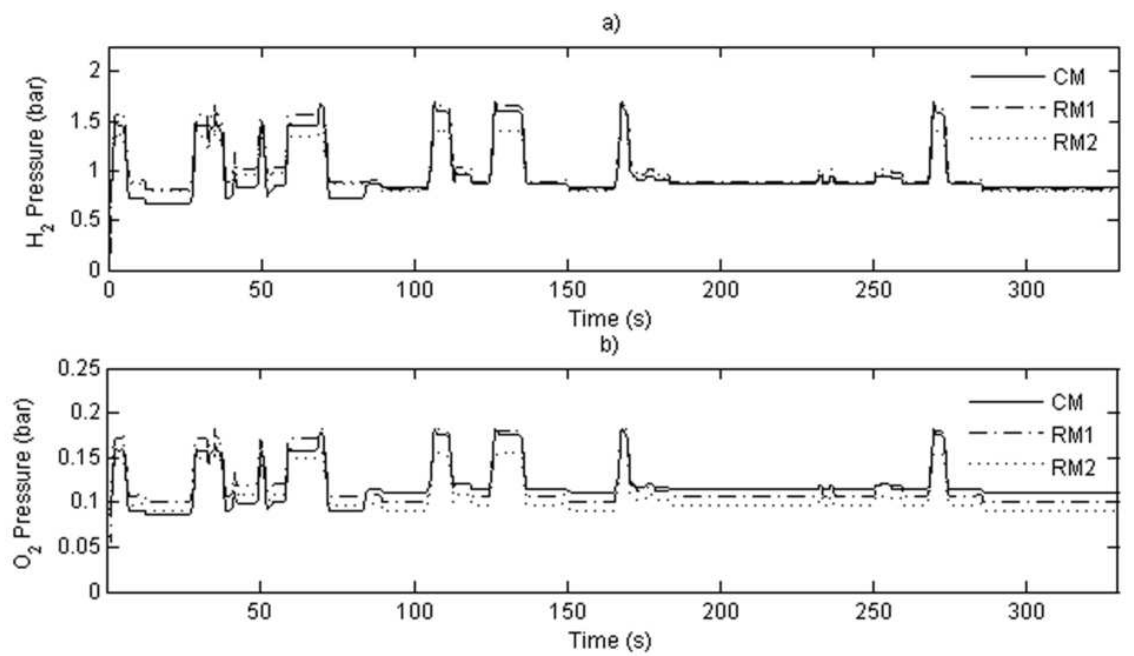

Fig. 12 (a) Hydrogen partial pressure, and (b) oxygen partial pressure at FC. $46 \times 24 \mathrm{~mm}(600 \times 600 \mathrm{DPI})$ 

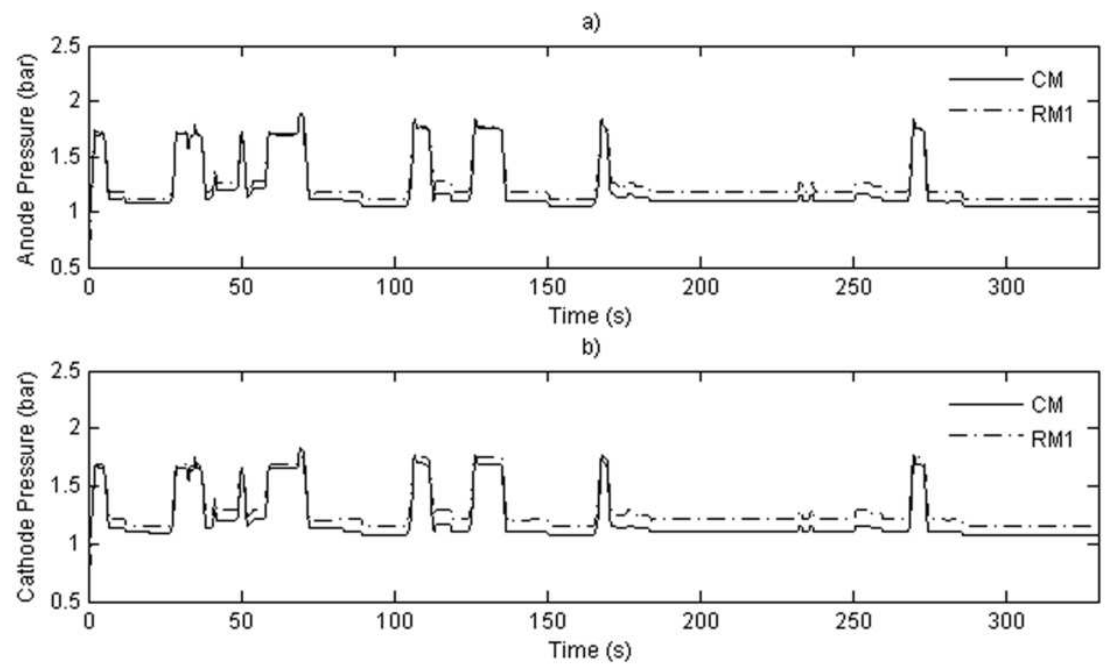

Fig. 13 (a) Anode pressure, and (b) cathode pressure at FC. $47 \times 24 \mathrm{~mm}(600 \times 600 \mathrm{DPI})$ 

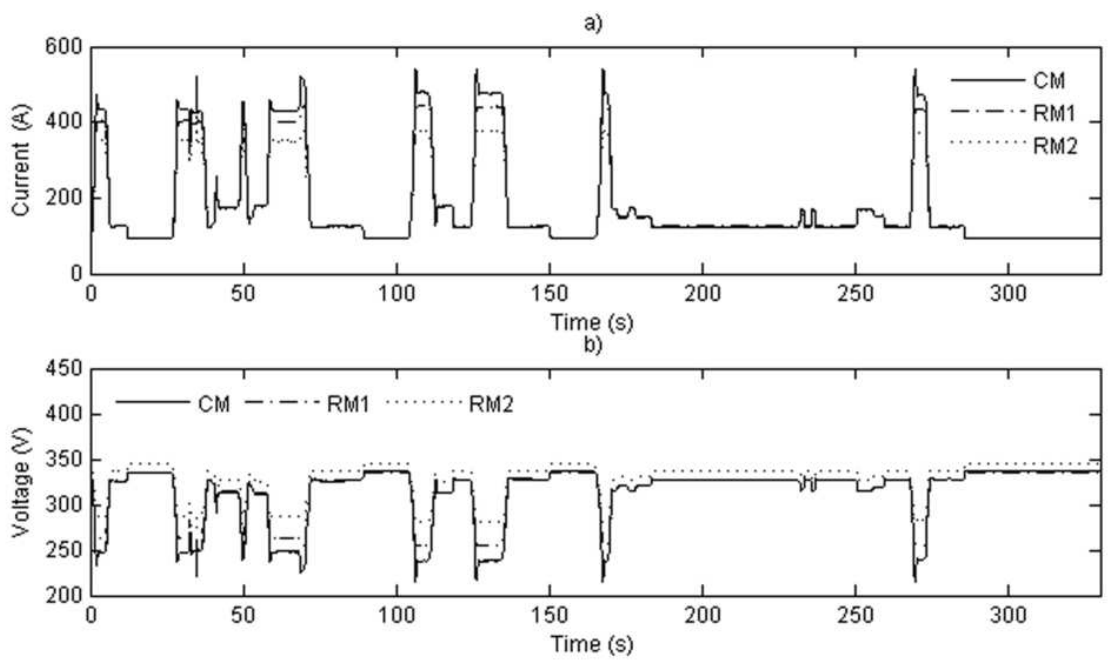

Fig. 14 (a) Total FC current, and (b) FC output voltage. $46 \times 24 \mathrm{~mm}(600 \times 600 \mathrm{DPI})$ 
Fig. 15 (a) Hydrogen mass entering, (b) FC efficiency and, (c) FC utilization factor. $65 \times 48 \mathrm{~mm}(600 \times 600 \mathrm{DPI})$ 

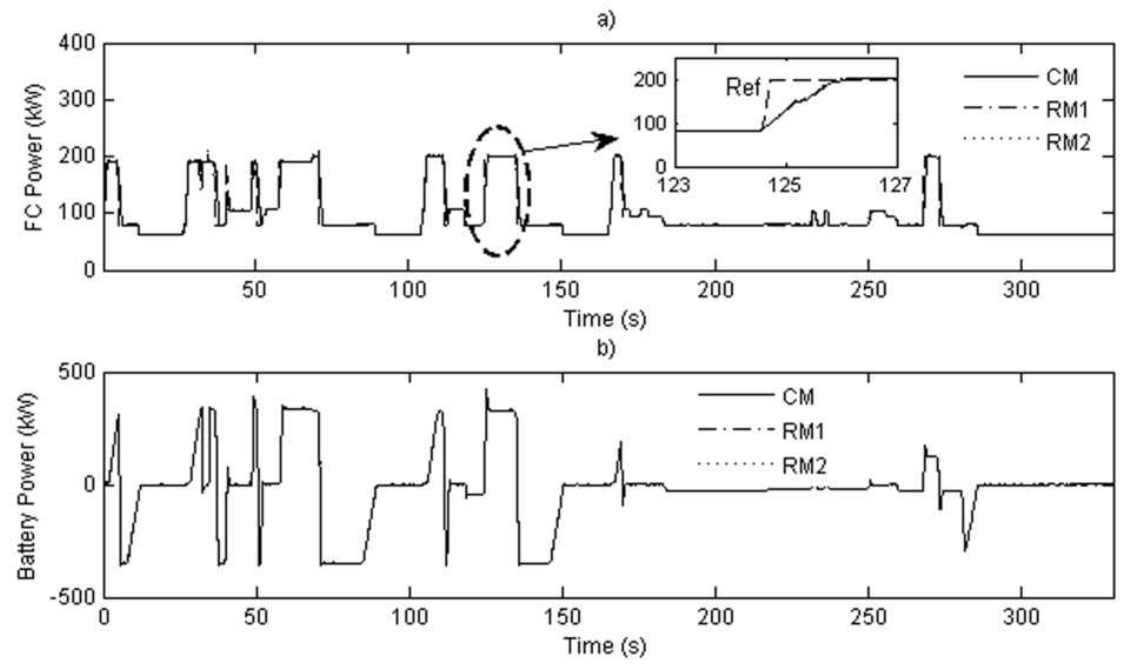

Fig. 16 (a) FC output power, and (b) battery power. $46 \times 24 \mathrm{~mm}(600 \times 600 \mathrm{DPI})$ 
Fig. 17 (a) Load power, and (b) power dissipated in the braking resistor. $46 \times 24 \mathrm{~mm}(600 \times 600 \mathrm{DPI})$ 